\title{
CORRELATION BETWEEN METAL-CERAMIC BOND STRENGTH AND COEFFICIENT OF LINEAR THERMAL EXPANSION DIFFERENCE
}

\author{
Stella Crosara LOPES ${ }^{1}$, Valéria Oliveira PAGNANO², João Manuel Domingos de Almeida ROLLO ${ }^{3}$, \\ Mônica Barbosa LEAL ${ }^{1}$, Osvaldo Luiz BEZZON ${ }^{4}$
}

\author{
1- DDS, MSc, PhD, Department of Dental Materials and Prosthodontics, Dental School of Ribeirão Preto, University of São Paulo, Ribeirão Preto, SP, \\ Brazil. \\ 2- DDS, MSc, PhD, Assistant Professor, Dental Materials and Prosthodontics, Dental School of Ribeirao Preto, University of São Paulo, Ribeirão \\ Preto, SP, Brazil. \\ 3- DDS, MSc, PhD, Associate Professor, Engineering School of São Carlos, University of São Paulo, São Carlos, SP, Brazil. \\ 4- DDS, MSc, PhD, Full Professor, Dental Materials and Prosthodontics, Dental School of Ribeirao Preto, University of São Paulo, Ribeirão Preto, \\ SP, Brazil.
}

Corresponding addres: Profa. Dra. Valéria Oliveira Pagnano - Departmento de Materiais Dentários e Prótese - Faculdade de Odontologia de Ribeirão Preto - USP- Avenida do Café, s/n - 14040-904- Ribeirão Preto - SP - Brasil - Phone: +55-16-3602-4795 - Fax: +55-16-3633-0999 - e-mail: valpag@forp.usp.br

Received: April 25, 2008 - Modification: July 10, 2008 - Accepted: August 30, 2008

\begin{abstract}
7

he purpose of this study was to evaluate the metal-ceramic bond strength (MCBS) of 6 metal-ceramic pairs $(2 \mathrm{Ni}-\mathrm{Cr}$ alloys and $1 \mathrm{Pd}-\mathrm{Ag}$ alloy with 2 dental ceramics) and correlate the MCBS values with the differences between the coefficients of linear thermal expansion (CTEs) of the metals and ceramics. Verabond (VB) Ni-Cr-Be alloy, Verabond II (VB2), Ni-Cr alloy, Pors-on 4 (P), Pd-Ag alloy, and IPS (I) and Duceram (D) ceramics were used for the MCBS test and dilatometric test. Forty-eight ceramic rings were built around metallic rods $(3.0 \mathrm{~mm}$ in diameter and $70.0 \mathrm{~mm}$ in length) made from the evaluated alloys. The rods were subsequently embedded in gypsum cast in order to perform a tensile load test, which enabled calculating the CMBS. Five specimens $(2.0 \mathrm{~mm}$ in diameter and $12.0 \mathrm{~mm}$ in length) of each material were made for the dilatometric test. The chromel-alumel thermocouple required for the test was welded into the metal test specimens and inserted into the ceramics. ANOVA and Tukey's test revealed significant differences $(\mathrm{p}=0.01$ ) for the MCBS test results (MPa), with PI showing higher MCBS (67.72) than the other pairs, which did not present any significant differences. The CTE $\left(10^{-6}{ }^{\circ} \mathrm{C}^{-1}\right)$ differences were: VBI (0.54), VBD (1.33), VB2I (-0.14), VB2D (0.63), PI (1.84) and $\mathrm{PD}$ (2.62). Pearson's correlation test $(\mathrm{r}=0.17)$ was performed to evaluate of correlation between MCBS and CTE differences. Within the limitations of this study and based on the obtained results, there was no correlation between MCBS and CTE differences for the evaluated metal-ceramic pairs.
\end{abstract}

Key words: Metal-ceramic. Bond strength. Ni-Cr alloy. Pd-Ag alloy. Dilatometric test.

\section{INTRODUCTION}

Metal-ceramic compatibility is an important factor in manufacturing metal-ceramic restorations. The coefficient of linear thermal expansion (CTE), thermal conductivity and the nature and strength of the bond are all factors that influence the porcelain's capacity to resist fracture during clinical use of the restoration ${ }^{11,21}$.

In agreement with many authors, the difference in CTEs of porcelain and metal has been recognized as a major parameter in predicting compatibility ${ }^{1,4,12,24}$. The general consensus is that the alloy should have higher CTE than the porcelain (a positive expansion coefficient mismatch) in order to produce compressive stress in the porcelain when cooling ${ }^{11,24}$. Usually, a variation ranging from 0.5 to $1.0 \mathrm{x}$ $10^{-6}{ }^{\circ} \mathrm{C}^{-1}$ between the CTEs of the alloy and ceramic is considered adequate when the metal coefficient is higher than that of the ceramic. It keeps the ceramic compressed; increasing the lifetime of the restoration ${ }^{3}$. Some authors reported that metal-ceramic specimens with a negative CTE difference failed at significantly lower flexural loads than specimens did with positive CTE difference ${ }^{2,10}$.

Various tests have been designed and selected by researchers to evaluate metal-ceramic bond strength and the minimal value recommended by the ISO standard $9693^{15}$ for metal-ceramic dental restorative systems is $25 \mathrm{MPa}$ for 3 -point bending test. However, it can be affirmed that this value is related more to the flexure strength of the metallic 
substrate than to the metal-ceramic bond strength ${ }^{12,13,18}$, causing difficulty when comparing different metallic substrates.

Noble metal alloys had been widely used for porcelain veneering in dentistry. However, with the continuous price fluctuations of noble metals, more attention has been given to alternative alloys. $\mathrm{Ni}-\mathrm{Cr}$ alloys have good mechanical properties, such as high degree of hardness, low density and high tensile strength. Also, the low cost and easy fabrication of Ni-Cr alloys have caused them to be widely used in dental fixed prosthesis for quite some time ${ }^{14}$.

The addition of $\mathrm{Be}$ in these $\mathrm{Ni}-\mathrm{Cr}$ alloys promoted castability improvement of these alloys and enhanced bonding strength between porcelain and metal ${ }^{3,6,14,17,20,23}$. However, in addition to beryllium, the presence of other potentially pathogenic metallic components in $\mathrm{Ni}-\mathrm{Cr}$ alloys has contributed for reinsertion of $\mathrm{Pd}-\mathrm{Ag}$ in the market ${ }^{5,8}$. Porcelains suitable for Pd-Ag alloys were then developed, which avoid wearing of the ceramic coverage by Ag diffusion in ceramics ${ }^{7,9}$ evidencing that this alloy system is safer than alloys with $\mathrm{Ni}^{7}$.

High palladium alloys were introduced in the early $1980 \mathrm{~s}$ and are currently widely used in metal-ceramic restorations, even though they have not yet been scientifically investigated to the extent that their widespread use requires ${ }^{10,13,14,17,18}$. This type of alloy presents characteristics that, in spite of not interfering with the porcelain-to-metal bond, must be observed. Moreover, there are elements in the alloy composition, such as silver and tin, which are susceptible to oxidation. Thus, previous oxidation is an important procedure that could increase the bond strength of such metal-ceramic interface ${ }^{1,16,19}$. Furthermore, the Pd-Ag alloy (Pors-on 4) presents much smaller grains than other Pd-Ag alloys that provide better mechanical qualities, besides promoting larger external contact surface ${ }^{14}$.

Another characteristic of the palladium alloy is its high sensitivity to the presence of carbon during casting procedures. This could generate problems such as ceramic porosities and carbon contamination in the alloy ${ }^{6,15,17,18}$. The carbon promotes a formation of carbon monoxide during the ceramic baking, creating bubbles and porosities, which could be partly responsible for undesirable outcomes, such as cracks or fractures.

The purpose of this study was to evaluate the metalceramic bond strength (MCBS) of 6 metal-ceramic pairs (2 $\mathrm{Ni}-\mathrm{Cr}$ alloys with/without Be and $1 \mathrm{Pd}-\mathrm{Ag}$ alloy with 2 dental ceramics) and correlate the MCBS values with the differences between the CTEs of the metals and ceramics.

\section{MATERIAL AND METHODS}

Two Ni-Cr alloys - Verabond (VB) with Be and Verabond II (VB2) without Be -and one Pd-Ag alloy - Pors-on 4 (P4) - were fused to 2 ceramics - IPS (I) and Duceram (D) (Table 1) to form six metal-ceramic pairs (VBI, VBD, VB2I, VB2D, PI, and PD). Eight specimens of each metal-ceramic pair were used to test shear bond strength. Five dilatometric specimens from each alloy and ceramic were used to measure the CTE. The bond strength data were analyzed for correlation with differences in CTE.

The metal-ceramic bond strength test was established on previously published techniques ${ }^{1,6,22}$, which determine the shear strength needed to break the metal-ceramic bond of a ceramic ring constructed around cylinder-shaped metal rods. The cast metal specimens were not submitted to any preheating treatment before applying ceramic. The ceramic rings were assembled with IPS porcelain and Duceram and manipulated according to the manufacturer's recommendations without any pre-heating treatment, since the Verabond manufacturer does not suggest pre-heating for single crowns, only for three-element fixed partial dentures. The ceramic firing cycles are listed in Table 2.

Each specimen was calibrated with a handheld digital caliper (Mitutoyo Digimatic Caliper, model 500-151, Mitutoyo Corp, Tokyo, Japan) as a function of the

TABLE 1- Commercial alloys, their compositions and manufacturers

Material Composition (wt \%) Manufacturer

Verabond

Verabond II

Ni 77.05; Cr 12.5; Mo 4.25; Nb 4.0; Al 2.25; Si 0.5; Ti 0.45

Pors-on 4

Pd 57.8; Ag 30.00; Rn 0.2; Sn 6.0; Zn 2.0; In 4.0

IPS

Duceram

$\mathrm{Al}_{2} \mathrm{O}_{3} ; \mathrm{B}_{2} \mathrm{O}_{3} ; \mathrm{BaO} ; \mathrm{CaO} ; \mathrm{CeO}_{2} ; \mathrm{K}_{2} \mathrm{O} ; \mathrm{MgO} ; \mathrm{Na}_{2} \mathrm{O}$; $\mathrm{P}_{2} \mathrm{O}_{5} ; \mathrm{SiO}_{2} ; \mathrm{TiO}_{2} ; \mathrm{ZrO}_{2}$
Ni 77.95 (maximum); Cr 12.6; Mo 5.0; Al 2.9; Be 1.95 (maximum); Co 0.45 ; Ti 0.35
Aalba Dent, Cordelia, CA, USA

Aalba Dent, Cordelia, CA, USA

Degussa S.A., Dusseldorf, Germany

Ivoclar 2/Fi, Shaan, Liechtenstein

$\mathrm{SiO}_{2} ; \mathrm{B}_{2} \mathrm{O}_{3} ; \mathrm{Al}_{2} \mathrm{O}_{3} ; \mathrm{K}_{2} \mathrm{O} ; \mathrm{Na}_{2} \mathrm{O} ; \mathrm{Li}_{2} \mathrm{O} ; \mathrm{BaO} ; \mathrm{CaO} ; \mathrm{SnO}_{2}$; $\mathrm{MgO} ; \mathrm{Sb}_{2} \mathrm{O}_{3} ; \mathrm{TiO}_{2} ; \mathrm{P}_{2} \mathrm{O}_{5} ; \mathrm{ZrO}_{2} ; \mathrm{F} ; \mathrm{Fe}_{2} \mathrm{O}_{3}$ 
TABLE 2- Ceramic firing cycles

\begin{tabular}{|c|c|c|c|c|}
\hline Ceramic & Layer & Firing temperature $\left({ }^{\circ} \mathrm{C}\right)$ & Firing time (min) & Maintenance time (min) \\
\hline \multirow{6}{*}{ IPS } & Opaque & & & \\
\hline & 1st layer & $550-980$ & $5^{*}$ & $1^{\circ}$ \\
\hline & 2nd layer & $550-970$ & $5^{*}$ & $1^{\ddot{0}}$ \\
\hline & Dentin & & & \\
\hline & 1st layer & $580-920$ & $5^{*}$ & $1^{\ddot{\theta}}$ \\
\hline & 2nd layer & $580-910$ & $5^{\star}$ & $1^{\circ}$ \\
\hline \multirow{6}{*}{ Duceram } & Opaque & & & \\
\hline & 1st layer & $600-930$ & $5^{*}$ & $1.5^{\circ}$ \\
\hline & 2nd layer & $600-925$ & $5^{*}$ & $1.5^{\circ}$ \\
\hline & Dentin & & & \\
\hline & 1st layer & $575-910$ & $5^{*}$ & $1^{\circ}$ \\
\hline & 2nd layer & $575-900$ & $5^{*}$ & $1^{\circ}$ \\
\hline
\end{tabular}

* Under vacuum. ${ }^{\circ}$ Without vacuum.

dimensional alterations inherent to the casting and ceramic firing processes. Eight individual specimens were cast for each alloy, being 1 for each casting ring.

Metal rods were obtained to place brass rods, measuring $3.0 \mathrm{~mm}$ in diameter and 70.0 in length, inside a phosphatebonded investment (Termocast; Polidental, Sao Paulo, Brazil). After investment hardening, using pliers, the brass rods were removed from the cast by the exposed end at the base of the casting ring. Casting rings were then burned out and cast. After the rings cooled, the castings were manually divested and airbone-particle abraded (Model Microjet II, EDG, São Carlos, SP, Brazil) with 100- $\mu$ m aluminum oxide abrasive (Polidental, Sao Paulo, SP, Brazil) under 2-bar pressure for $5 \mathrm{~s}$, to remove residual investment. No preheating treatment was performed.

For the fabrication of ceramic rings, silicone rubber cylinders measuring $7.0 \mathrm{~mm}$ in diameter and $6.0 \mathrm{~mm}$ high were fabricated, with a hole in the middle equal to the diameter of the rods in order to form a mold for the ceramic material. Each metal rod received a pair of these cylinders, each positioned by its free end to prevent any contamination from the construction site of the ceramic ring. One cylinder was positioned nearby the extremity of the metallic rod and the other one was inserted at the other end and moved until it encountered the spacer selected to standardize the thickness of the ceramic ring to $1.5 \mathrm{~mm}$.

Using a dental surveyor, the rings, assembled $6.0 \mathrm{~mm}$ from one end of the rods, were placed in the center of a plaster cylinder for load application. All steps of the metalceramic bond strength test are schematically illustrated in Figures 1 to 4 . After plaster curing, the specimens were subjected to tensile loading in a universal testing machine (EMIC MEM 2000, São Jose dos Pinhais, PR, Brazil) by introducing opposite clamps, a self-locking one at the exposed end of the rod and another one projected to accommodate the plaster cylinders. The machine was set at a cross-head speed of $0.5 \mathrm{~mm} / \mathrm{min}$. The peak load was recorded and used to calculate the bond strength- indicating MCBS by the equation: $\mathrm{T}=\mathrm{F} / \mathrm{s}$, where $\mathrm{T}=$ bond strength, $\mathrm{F}$ $=$ critical rupture load, and $\mathrm{s}=$ area of the metal-ceramic bond. Thus, an area was obtained with the equation: $s=p$. $\mathrm{d}$. $\mathrm{t}$, where $\mathrm{s}=$ metal-ceramic bonding area, $\mathrm{d}=$ rod diameter,

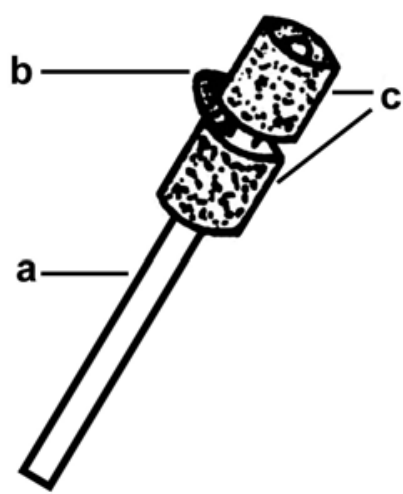

FIGURE 1- Ensemble mounted for opaque application and ceramic condensation: a) metal rod, b) spacer, c) cylinders of silicone

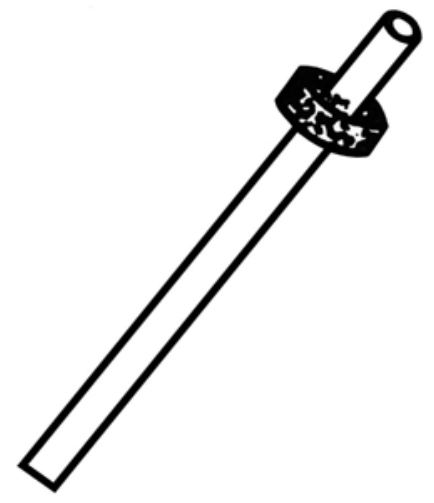

FIGURE 2- Porcelain ring constructed around metal rod 


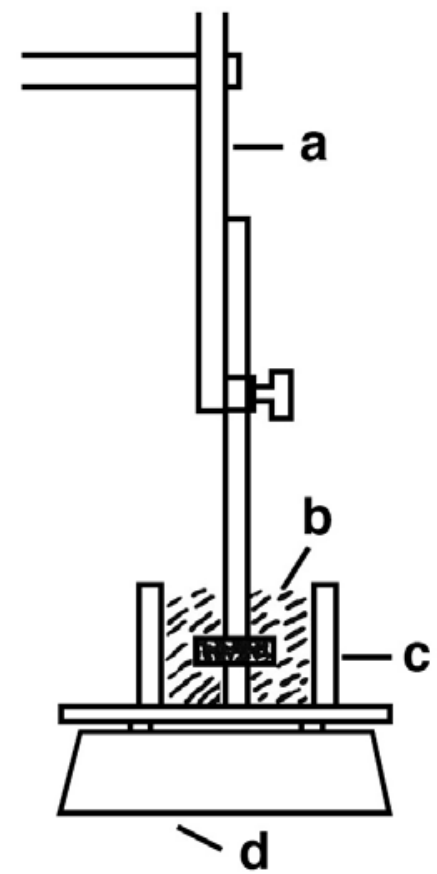

FIGURE 3- Ensemble mounted for ceramic ring embedding in gypsum cylinder: a) surveyor, b) gypsum, c) PVC ring, d) vibrator

and $\mathrm{t}=$ ring thickness.

The data were recorded and submitted to a one-way ANOVA and Tukey's test $(\alpha=0.01)$.

Specimens measuring $12 \mathrm{~mm}$ in length and $2 \mathrm{~mm}$ in diameter were fabricated for the dilatometric test. Alloy specimens were obtained by machining the previously cast metallic stems from the studied alloys, in the mechanical vise. A capillary chromel-alumel thermocouple $(0.8 \mathrm{~mm}$ in diameter) was welded to the specimen to check the temperature variation. Welding was accomplished by a micro-welder attached to the dilatometer. $\mathrm{C}$ e $\mathrm{r}$ a $\mathrm{m} \mathrm{i} \mathrm{c}$ specimens were obtained by $2-\mathrm{mm}$-diameter built-in irrigation cannulas (model 22G1; Sr Produtos Hospitalares, Manaus, AM, Brazil) in refractory material (Fortune, Williams Dent Co, Buffalo, NY, USA). The cannulas were removed after refractory setting, leaving the required space for further application of the ceramic.

The investment was wet and the ceramic was applied in 2 steps. After the second firing of porcelain, finishing with low-speed diamond burs was done for final dimension adjustments. When the final dimensions were obtained, a groove was made in the center of the specimen for accommodation and building-in of the thermocouple, previously welded with porcelain gold flush. An additional porcelain layer was added, in order to retain the thermocouple inside it, which required a new firing for ceramic sintering.

A dilatometer (Adamel Lhomargy, model DT 1000, NY, USA) was used for the dilatometric testing. Prior to the dilatometric tests, a complete heating/cooling cycle was performed in order to establish the temperature of each ceramic softening. The specimens were placed on the

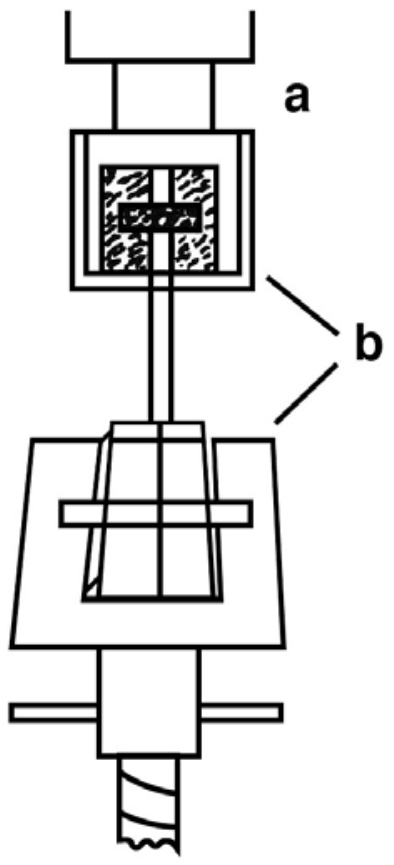

FIGURE 4- Ensemble mounted for application of tensile load: a) universal testing machine, b) traction clamps

dilatometer and the cycle was performed, beginning at room temperature. The heating rate was $5^{\circ} \mathrm{C} / \mathrm{min}$, up to the moment that an inversion on the heating curve was noted on the monitoring screen. At this point, the test was interrupted and each porcelain softening temperature was determined. IPS softening temperature was $654.9^{\circ} \mathrm{C}$ and Duceram's was $644.8^{\circ} \mathrm{C}$. Therefore a safe number for maximum temperature of the dilatometric test with ceramics was established at $620^{\circ} \mathrm{C}$.

Regarding the dilatometric test for ceramic specimens, a heating/cooling cycle was programmed at a heating rate of $5^{\circ} \mathrm{C} / \mathrm{min}$ starting at room temperature and advancing to $620^{\circ} \mathrm{C}$. At this temperature, the specimen was cooled down at a cooling rate of $5^{\circ} \mathrm{C} / \mathrm{min}$. and the determination of CTE was made from $500^{\circ} \mathrm{C}$ down to room temperature with air and helium gas injection.

Metallic alloys were submitted to the entire cycle, which simulated the firing of ceramics. They were heated from room temperature up to $580^{\circ} \mathrm{C}$ under vacuum at a heating rate of $150^{\circ} \mathrm{C} / \mathrm{min}$ and then up to $920^{\circ} \mathrm{C}$ at heating rate of $5^{\circ} \mathrm{C} / \mathrm{min}$. After reaching $920^{\circ} \mathrm{C}$, vacuum was eliminated; the specimen was kept for one minute at this temperature and then cooled down to $500^{\circ} \mathrm{C}$. From this temperature, the CTE was determined to a cooling rate of $5^{\circ} \mathrm{C} / \mathrm{min}$ to room temperature. The CTE was the mean value of five specimens for each evaluated material.

The data were recorded and submitted to one-way ANOVA and Tukey's test $(\alpha=0.05)$. Additionally, linear regression was performed to determine the correlation of MCBS and CTE differences. 
TABLE 3- Results of ANOVA

\begin{tabular}{lccccc}
\hline Factors & Sum of squares & $\boldsymbol{d f}$ & Mean square & F & $\boldsymbol{P}$ \\
\hline Pairs & 5993.92 & 5 & 1198.78 & 11.90 & .001 \\
Residue & 4229.56 & 42 & 100.70 & & \\
Total variation & 10223.48 & 47 & & \\
\hline
\end{tabular}

TABLE 4- Metal-ceramic bond strength (MPa) results

\begin{tabular}{ll}
\hline Metal-ceramic pair & Mean (SD) \\
\hline VBI & $38.61(10.11)^{\mathrm{b}}$ \\
VBD & $43.12(5.04)^{\mathrm{b}}$ \\
VB2I & $39.20(10.44)^{\mathrm{b}}$ \\
VB2D & $41.65(7.11)^{\mathrm{b}}$ \\
PI & $67.72(16.19)^{\mathrm{a}}$ \\
PD & $32.73(7.37)^{\mathrm{b}}$ \\
\hline
\end{tabular}

${ }^{a-b}$ Groups with same superscript letter are not statistically different $(p>.01)$

TABLE 6- Differences among dilatometric coefficients of alloys and ceramics $\left(10^{-6}{ }^{\circ} \mathrm{C}^{-1}\right)$

\begin{tabular}{ll}
\hline Metal-ceramic pair & CTE Difference \\
\hline VBI & 0.54 \\
VBD & 1.33 \\
VB2I & -0.14 \\
VB2D & 0.63 \\
PI & 1.84 \\
PD & 2.62 \\
\hline
\end{tabular}

\section{RESULTS}

\section{Metal-Ceramic Bond Strength (MCBS) Test}

Eight repetitions were performed for each of the 6 groups. The ANOVA and Tukey's test indicated statistically significant differences among the groups $(\mathrm{p}<0.01)$ (Tables 3 and 4). The PI par showed the highest MCBS (67.72 MPa). All other metal-ceramic pairs showed no significant differences.

\section{Dilatometric Test}

Table 5 shows the single material CTE values and also means and standard deviations of the evaluated materials. Table 6 shows the differences among CTE values of ceramics and alloys, within the range of $100^{\circ} \mathrm{C}$ to $500^{\circ} \mathrm{C}$, resulting from the mean of the five specimens for each evaluated material.

For the correlation analysis of MCBS and CTE differences, the Pearson test was performed. There was not
TABLE 5- Mean and standard deviation of CTE materials $\left(10^{-5}{ }^{\circ} \mathrm{C}^{-1}\right)$

\begin{tabular}{ll}
\hline Material & Mean (SD) \\
\hline VB & $1.31(0.06)$ \\
VB2 & $1.24(0.05)$ \\
P & $1.44(0.07)$ \\
I & $1.26(0.08)$ \\
D & $1.18(0.08)$ \\
\hline
\end{tabular}

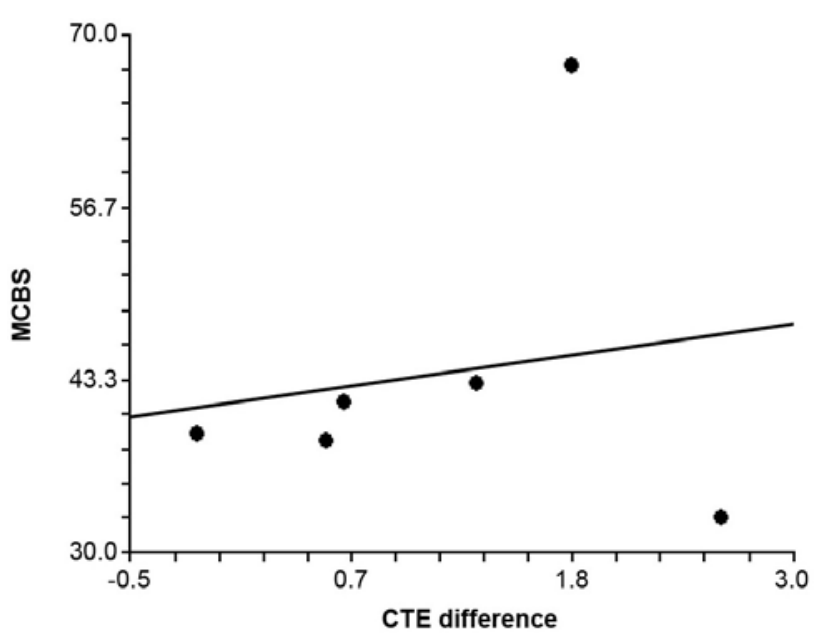

FIGURE 5- Scatter plot of the correlation between MCBS (MPa) and CTE differences $\left(10^{-6}{ }^{\circ} \mathrm{C}^{-1}\right)$

correlation between them $(\mathrm{r}=0.17)$. Figure 5 shows the scatter plot with a regression model superimposed.

\section{DISCUSSION}

The emergence of metal-ceramic restorations in the late 50 's created the need to control CTE of metal alloys in order to guarantee the success of restorations by preventing the rupture of metal-ceramic bond ${ }^{3}$.

Thermal compatibility of the metal-ceramic pair could play a significant role in MCBS because it constitutes the main physical requirement to avoid stress at the interface ${ }^{11,12,18,24}$. The CTEs of the metal and ceramics must be similar in order to avoid stress ${ }^{2,4,11,12,23}$. The recommended 
mean difference between alloy and ceramics CTEs (from room temperature to $600^{\circ} \mathrm{C}$ ) is from 0.5 to $1.010^{-6}{ }^{\circ} \mathrm{C}^{-13,23}$.

The CTE differences between VB alloy and IPS ceramic $\left(0.54 \times 10^{-6}{ }^{\circ} \mathrm{C}^{-1}\right)$ and between VB2 and Duceram $(0.63 \mathrm{x}$ $\left.10^{-6} \mathrm{C}^{-1}\right)$ were found within the above mentioned range but did not guarantee high values of CMBS. The VBD pair difference was $1.33 \times 10^{-6}{ }^{\circ} \mathrm{C}^{-1}$ while the VB2I pair showed a negative difference $\left(-0.14 \times 10^{-6}{ }^{\circ} \mathrm{C}^{-1}\right)$. Although some authors ${ }^{3,10}$ recommend that the metal and porcelain should have similar coefficients of thermal contraction and metal must have a slightly higher value to avoid undesirable tensile loading at the interface, in this case the CTE of ceramic was higher than the alloy one, without significant differences observed in the MCBS values.

Two situations can be found when comparing the CTE differences in this study. When there is a positive difference of CTEs, the CTE of alloy is higher than the CTE of ceramic, where ceramic is compressed and metal is under tension. This is found to be the most common combination in dental metal-ceramic systems. When the difference is negative, the CTE of ceramic is higher than the CTE of alloy, where ceramic is under tension and metal is compressed ${ }^{4}$.

Differences much higher than the recommended average were found at the combination Pors-on 4 alloy and both studied ceramics $\left(\mathrm{PI}=1.8 \times 10^{-6}{ }^{\circ} \mathrm{C}^{-1}\right.$; and $\mathrm{PD}=2.6 \times 10^{-6{ }^{\circ}} \mathrm{C}^{-}$ $\left.{ }^{1}\right)$. Differences of $1.7 \times 10^{-6}{ }^{\circ} \mathrm{C}^{-1}$ between the coefficients of the metal-ceramic pair produce tension in the porcelain close to the metal-ceramic interface during the cooling of porcelain, possibly causing spontaneous bonding failure ${ }^{1}$. It is also known that differences in CTE between ceramic, metal and metallic oxide may induce stress on the metalceramic interface ${ }^{11,12,24}$.

There is no doubt that in order to guarantee esthetic results, the metal-ceramic bond strength is a basic factor because any failure with this bond may lead to an earlier removal of the restoration, regardless the success of initial results. However, there is no agreement regarding the adhesion mechanism between the metal and porcelain ${ }^{3,6,17,22}$.

There are questions regarding the testing methods for evaluation of the actual strength of metal-ceramic bond, since a method that can accurately measure this property is as of yet unknown. Some authors state that there is no methodology capable of measuring only shear forces along the metal/porcelain interface e $^{3,13}$.

In this study, the tensile load test with ceramic rings applied around metallic stems represents actual situations of metal-ceramic restorations with a larger esthetic covering of the process. No pre-heating was performed on the evaluated alloys, contradicting the respective manufacturer's indications of the Pors-on 4 alloy. The purpose of this criterion was to minimize the effect of the chemical interaction among the evaluated materials, thus enabling greater physical interaction activity of the components ${ }^{20,24}$. The manufacturer of the VB and VB2 alloys does not suggest pre-heating for single unit, only for multiple unit frameworks. However, according to a previous study ${ }^{14}$, the presence of $\mathrm{Al}$ (as $\mathrm{Al}_{2} \mathrm{O}_{3}$ ) and $\mathrm{Be}$ (as $\mathrm{BeO}$ ) on the oxide layer of $\mathrm{Ni}-\mathrm{Cr}$ alloy specimens submitted to pre-heating resulted to a better porcelain/metal bonding behavior. Therefore, it is possible that for each evaluated metallic substrate, the MCBS values could be improved if the pre-heating treatment was used. Therefore, it is possible that for each evaluated metallic substrate, the MCBS values could be improved if the manufacturer's recommendations were followed.

By analyzing the loads involved in the metal-ceramic bond strength, there was no significant difference among five of the six evaluated metal-ceramic pairs. The association of alloy Pors-on 4 with ceramic IPS provided higher MCBS than the other combinations. On the other hand, no advantage was observed in using the alloy with Be. This is an important issue, considering the involved potential health risk. However, this result is different those of a previous study ${ }^{14}$, which performed pre-heating treatment of the alloys and reported that the presence of the Be reduced the oxide layer, hence promoting better metal-ceramic bonding. This fact might have occurred because in the present study the preheating treatment of the alloys was not performed, as previously explained, aiming at minimizing the effect of the chemical interaction among the evaluated materials.

Although this higher difference is adverse for restoration longevity, the Pors-on 4/IPS pair presented the highest MCBS values (difference of $1.84 \times 10^{-6}{ }^{\circ} \mathrm{C}^{-1}$ ) while the PD pair (difference of $2.6 \times 10^{-6}{ }^{\circ} \mathrm{C}^{-1}$ ) showed $\mathrm{CMBS}$ values without any significant difference in relation to the previously considered pairs, with CTE differences considered as more adequate. Therefore, in this case, it was not possible to correlate the two evaluated parameters.

When building metal-ceramic pairs at high temperatures of opaque or dentin layer firing $\left(900\right.$ to $\left.950^{\circ} \mathrm{C}\right)$, porcelain is found in a softened state and it is adequately molded to the metallic substrate. From $600^{\circ} \mathrm{C}$, when porcelain hardening occurs, the differences of the metal-ceramic pair can generate the occurrence of complex tensions, which makes it difficult to perceive the consequences of the genuine characteristic of the metal-ceramic bond.

If the highest difference of CTE results in bonding failure was due to the occurrence of cracks $^{11}$, it is possible that, in the case of PI, cracks did not occur and the porcelain maintained under tension presented the best results. However, it is possible that, if submitted to wear, a restoration made of this combination would undergo fracture due to the sum of chewing stress and the intrinsic stress of the metalceramic interface. In view of this possibility, the supposition that dynamic evaluations are perhaps better indicated to assess the actual quality and consequent longevity of metalceramic bond should be considered.

It was difficult to compare the results of the present study to those obtained in other studies because different methods have been used to evaluated metal-ceramic bond strength. In the present study no pre-heating treatment was performed because it was not the aim of this study to add another variation factor, since not all of the manufacturers of studied alloys recommend pre-heating. Furthermore, the obtained results cannot be directly interpreted as clinically relevant, since factors such as the test geometry, the lack of a moist environment and lack of fatigue loading were not evaluated. 
Although the number of studied pairs was small, the goal of this work was not to generalize that there is not relation between MCBS and CTE differences, but rather to show that the differences were not the main factor and to emphasize the importance of chemical relation between the evaluated pairs. Additionally, this study aimed to demonstrate the problem. Further research should determine the importance of the bonding mechanisms and the compatibility of various metal-ceramic combinations. The data from these new studies might provide criteria for the rational selection of ceramics and alloys that have adequate bond strength for clinical use.

\section{CONCLUSIONS}

Considering the study methodology and limitations, it was concluded that:

1. There was statistically significant difference only for the IPS ceramic/ Pors-on 4 alloy pair, which showed the highest value of metal-ceramic bond strength. All other metal-ceramic pairs showed no significant differences.

2. It was not possible to establish any correlation between the metal-ceramic bond strength values and CTE differences of the evaluated metal-ceramic pairs.

\section{ACKNOWLEDGEMENTS}

This investigation was supported by grant No. 00/ 002471-0 from FAPESP (The State of São Paulo Research Foundation).

\section{REFERENCES}

1- Anthony DH, Burnett AP, Smith DL, Brooks MS. Shear test for measuring bonding in cast gold alloy-porcelain composites. J Dent Res. 1970;49:27-33

2- Anusavice KJ, DeHoff PH, Fairhurst CW. Comparative evaluation of ceramic-metal bond tests using finite element stress analysis. J Dent Res. 1980;59:608-13

3- Anusavice KJ. Dental casting and soldering alloys. In: Phillips Science of Dental materials. $11^{\text {th }}$ ed. Philadelphia: Saunders; 2003. p. 563-620.

4- Anusavice KJ, Shen C, Hashinger D, Twiggs SW. Interactive effect of stress and temperature on creep of PMF alloys. J Dent Res. 1985;64:10949 .

5- Bezzon OL. Allergic sensitivity to several base metals: a clinical report J Prosthet Dent. 1993;69:243-4

6- Bezzon OL, de Mattos MG, Ribeiro RF, Rollo JM. Effect of beryllium on the castability and resistance of metal-ceramic bonds in nickelchromium alloys. J Prosthet Dent. 1998;80:570-4.

7- Brantley WA, Cai Z, Papazoglou E, Mitchell JC, Kerber SJ, Mann GP, et al. X-ray diffraction studies of oxidized high-palladium alloys. Dent Mater. 1996;12:333-41.

8- Carr AB, Brantley WA. New high-palladium casting alloys: 1. Overview and initial studies. Int J Prosthodont. 1991:4:265-75.
9- Carr AB, Cai Z, Brantley WA, Mitchell JC. New high-palladium casting alloys: Part 2. Effects of heat treatment and burnout temperature. Int J Prosthodont. 1993;6:233-41.

10- Coffey JP, Anusavice KJ, De Hoff PH, Lee RB, Hojjatie B. Influence of contraction mismatch and cooling rate on flexural failure of PFM systems. J Dent Res. 1988;67:61-5.

11- DeHoff PH, Anusavice KJ, Hojjatie B. Thermal incompatibility analysis of metal-ceramic systems based on flexural displacement data. $\mathrm{J}$ Biomed Mater Res. 1998; 41:614-23.

12- Fairhurst CW, Anusavice KJ, Hashinger DT, Ringle RD, Twiggs SW. Thermal expansion of dental alloys and porcelains. J Biomed Mat Res. 1980; $14: 435-46$.

13- Hammad IA, Talic YF. Designs of bond strength tests for metal-ceramic complexes: review of the literature. J Prosthet Dent. 1996;75:602-8.

14- Huang HH, Lin MC, Lee TH, Yang HW, Chen FL, Wu SC, et al. Effect of chemical composition of Ni-Cr dental casting alloys on the bonding characterization between porcelain and metal. J Oral Rehabil. 2005;32:206-12.

15- International Standartization Organization. 9693:1999/Amd.1:2005. Metal-ceramic dental restorative systems. $2^{\text {nd }}$ ed. Geneve: ISO; 1999/2005. $14 \mathrm{p}$.

16- Johnson T, van Noort R, Stokes CW. Surface analysis of porcelain fused to metal systems. Dent Mater. 2006;22:330-7.

17- Mackert Jr, Ringle RD, Fairhurst CW. High-temperature behavior of a Pd-Ag alloy for porcelain. J Dent Res. 1983;62:1229-35.

18- Oilo G, Johansson B, Syverud M. Bond strength of porcelain to dental alloys - an evaluation of two test methods. Scand J Dent Res. 1981;89:28996.

19- Papazoglou E, Brantley WA, Johnston WM, Carr AB. Effects of dental laboratory processing variables and in vitro testing medium on the porcelain adherence of high-palladium casting alloys. J Prosthet Dent. 1998;79:514-9.

20- Payan J, Moya GE, Meyer JM, Moya F. Changes in physical and chemical properties of a dental palladium-silver alloy during metalporcelain bonding. J Oral Rehabil. 1986;13:329-38.

21- Porcelain-metal alloy compatibility: criteria and test methods. Council on Dental Materials, Instruments, and Equipment. J Am Dent Assoc. $1981 ; 102: 71-2$

22- Shell JS, Nielsen JP. Study of the bond between gold alloys and porcelain. J Dent Res. 1962;41:1424-37.

23- Steiner PJ, Kelly JR, Giuseppetti AA. Compatibility of ceramicceramic systems for fixed prosthodontics. Int J Prosthodont. 1997; 10:37580

24- Walton TR, O'Brien WJ. Thermal stress failure of porcelain bonded to a palladium-silver alloy. J Dent Res. 1985;64:476-80. 